\title{
INDEX OF VOLUME 50
}

\section{Subjects:}

\section{INDEX OF ABSTRACTS ${ }^{1}$}

Algebra and Theory of Numbers, 51, 179, 332, 495, 664, 821 .

Analysis, 55, 180, 336, 497, 666, 823.

Applied Mathematics, 61, 185, 344, 499, 672, 825.

Ergodic Theory, 63.

Geometry, 63, 188, 346, 500, 674, 826.

Logic and Foundations, 827.

Statistics and Probability, 191, 347, 678, 827.

Topology, 64, 192, 348, 501, 679, 827.

Authors:

Agnew, R. P., 471 (336), 808 (497), 809 (497), 809 (666), 809 (666), 809 (667), (823), (823); Alaoglu, L., 474 (332); Albert, A. A., 31 (51), 32 (51); Ambrose, W., 474 (495), 809 (664); Arens, R. F., (827); Aroian, L. A., (827); Avann, S. P., 471 (332).

Baer, R., 474 (332), 474 (346), 474 (495); Beaumont, R. A., (821); Beckenbach, E. F., 474 (336), 475 (336), 476 (348), 809 (667), (823); Bell, E. T., 809 (664); Bell, P. O., 474 (346); Bergman, S., 21 (55), 319 (185), 319 (188), 472 (337), 472 (337), 809 (667), (825); Bernstein, B. A., 319 (54), 476 (333); Bers, L., 21 (56), 22 (56); Bing, R. H., 476 (348), 809 (667); Birkhoff, G., 471 (332); Bissinger, B. H., 474 (337); Blumenthal, L. M., 809 (664); Boas, R. P., (824); Bobonis, A., 472 (338); Bourgin, D. G., 31 (56); Brandt, A. J., 31 (49; 849); Brauer, A., 32 (56); Brenner, J. L., 30 (51); Bruck, R. H., 31 (49; 849), 31 (52), 474 (333), 475 (333), (821), (821); Brunk, H. D., 472 (338), 475 (339), 476 (338); Buck, R. C., $21(49 ; 853)$, $22(49 ; 852), 22(49 ; 852)$, 22 (49; 864); Busemann, H., 809 (674).

Cameron, R. H., 471 (339), 808 (667), 809 (668); Caton, W. B., 30 (56); Chern, S. S., 318 (189), 471 (346); Chevalley, C., 31 (52), 809 (674); Churchman, C. W., 319 (191), 472 (347), 808 (678); Clark, C. L., 319 (192); Coburn, N., 319 (185), 810 (672); Cohen, L. W., 30 (61); Coleman, A. J., 810 (673), 810 (673); Colvin, B. H., 32 (57); Copeland, A. H., 30 (61); Curry, H. B., 31 (49; 859).

Day, M. M., 31 (52), 471 (339), 475 (339), 475 (339); DeCicco, J., 21 (49; 697), 29 (49; 864), 31 (49; 864), 318 (190), 319 (190), 472 (500), 810 (674); Dennis, J. J., 810 (668); Dilworth, R. P., 161 (52); DiPaola, J., 809 (500); Douglas, J., 318 (180); Dresden, M., 474 (344); Dubisch, R., 161 (53); Duffin, R. J., 809 (496), 810 (495); Dunford, N., 810 (668).

Eilenberg, S., 30 (53), 474 (349), 809 (679); Ellis, W., 31 (53); Epstein, B., 319 (191), 472 (347), 808 (678); Erdös, P., 30 (57), 474 (332), (669); Everett, C. J., 811 (496); Eves, H. W., 810 (665), 810 (675), 810 (675), (825).

Federer, H., 22 (49; 853), $22(49 ; 854), 476$ (340); Feld, J. M., 318 (189); Fine, N. J., 31 (54); Fite, W. B., 472 (333); Foster, A. L., 319 (54), 476 (333), (822); Fox, R. H., 30 (49; 867); Friedman, B., 31 (49; 859); Friedrichs, K. O., 319 (180); Frissel, H. F., 809 (500).

Garabedian, H. L., 319 (186); García, M., 319 (192), 810 (679); Gelbart, A., 21 (56), 22 (56); Goldberg, M., 472 (186); Gottschalk, W. H., 319 (192), 809 (680), 810 (501), 810 (680); Grove, V. G., 31 (63); Gumbel, E. J., 319 (191), 808 (678).

Haimo, F., 22 (49; 37); Hall, D. W., 319 (193); Hallet, E., (827); Halmos, P. R.,

${ }^{1}$ Numbers within parentheses refer to the page numbers for abstracts, and those outside parentheses refer to the pages for titles as listed in reports of meetings. 
30 (63), 471 (348); Heins, M. H., 31 (49; 854); Herriot, J. G., 476 (340); Herzberger, M., 319 (186); Herzog, F., 474 (337); Hill, J. D., 475 (340), 475 (340); Hille, E., 30 (56), 810 (668); Hsiung, C. C., 319 (189), 810 (675), 810 (676), (676); Hsu, P. L., 808 (678); Hua, L. K., (822), (822); Huff, G. B., 475 (190); Hughes, H. K., 474 (341); Hull, R., 31 (54).

Ingersoll, B. M., 318 (180), 808 (669), (824); Ingram, W. H., 810 (669); Isaacs, R. P., 319 (186).

Jackson, D., 319 (341); Jackson, S. B., 472 (347); Jacobson, N., 810 (665), (822); James, R. C., 161 (57), 476 (349); James, R. D., 477 (334); Jeffery, R. L., (669); Jennings, S. A., 477 (334); Johnson, R. E., 31 (49; 850); Jones, A. W., 318 (179); Jones, B. W., 809 (665).

Kac, M., 319 (181); Kalisch, G. K., 474 (334); Kaplan, W., 474 (344); Kasner, E., $21(49 ; 697), 31$ (49; 864), 318 (190); 319 (190), 472 (500), 810 (676); Kelly, P. J., (828); Kober, H., 472 (341).

Lane, R. E., 810 (824); Levenberg, K., 30 (49; 861), Levinson, N., 21 (49; 855), Levitzki, J., 319 (54), (823), Lewis, A. L., 30 (58), Lonseth, A. T., 30 (58), 320 (181), Loomis, L. H., 471 (342), Lowan, A. N., 22 (49; 694), 472 (342), 810 (499).

MacColl, L. A., 21 (49; 865), MacDonald, J., 29 (63), Mackey, G. W., 472 (342), MacLane, S., 30 (53), Mandelbrojt, S., 320 (181), Marden, M., 31 (58), 474 (345); Martin, W. T., 471 (339), 808 (667), 809 (668); Meder, A. E., (827); Mendel, C. W., 31 (56); von Mezynski, I., 810 (676); Michal, A. D., 477 (345); Miller, D. S., 811 (670), (669); Millsaps, K. T., 162 (64), 477 (334); Min, S. H., (822); Mises, R. v., 320 (187); Moore, C. N., 808 (670); Moore, R. L., 32 (64); Morse, A. P., 22 (49; 856), $22(49 ; 856) ;$ Moskovitz, D., 319 (187); Murray, F. J., $22(49 ; 856)$; Myers, S. B., 811 (681).

Newell, H. E., 320 (181); Newhouse, A., 475 (335); Nielsen, K. L., 30 (59); Nilson, E. N., 811 (670); Niven, I., 31 (54).

Opatowski, I., 29 (62), 320 (187); Ore, O., 320 (179); Overholtzer, G., (665).

Pall, G., 808 (666); Pate, R. S., 809 (496), 810 (495); Peiser, A. M., 318 (182), 472 (342); Perlis, S., 161 (53); Pollard, H., 21 (49; 853), 320 (182), 808 (671), (824); Pounder, J. R., (826); Purcell, E. J., 162 (64).

Rado, T., 474 (497); Rainich, G. Y., 30 (54); Randolph, J. F., 22 (49; 856); Reade, M., 474 (336), 474 (343), 475 (336), 475 (343); Reed, I. S., 477 (497); Reid, W. T., 30 (59); Reissner, E., 809 (673); Richardson, M., 811 (673); Rickart, C. E., 318 (182); Robbins, H E., 319 (191), 320 (182); Roettinger, I., 475 (345); Rosenbloom, P. C., 808 (671).

Safford, F. H., 320 (182), Salem, R., 318 (179), 320 (183), 320 (183), (824), Salzer, H. E., 22 (49; 694), $22(49 ; 698), 32$ (55), 320 (62), 320 (188), 472 (342), 810 (499), 811 (499), 811 (499); Satterthwaite, F. E., 808 (678); Schafer, A. T., 29 (49; 865); Scheffe, H., 471 (348); Scherk, P., 811 (677); Schilling, O. F. G., 811 (496), 811 (496); Schoenberg, I. J., (825), (826); Schoenfeld, L. I., 471 (343); Schweigert, G. E., 30 (65); Schweitzer, A. R., 32 (59), 320 (183), 320 (183), 811 (497), 811 (498), 811 (498); Seidenberg, A., 809 (500); Shanks, M. E., 30 (64), 31 (49; 867); Sherman, S., 809 (500); Shiffman, M., 21 (49; 857); Shohat, J. A., 21 (49; 863), 471 (346); Smiley, M. F., 318 (184), 475 (335); Steenrod, N. E., 474 (349), 809 (679); Stephens, C. F., 475 (343); Sternberg, W., 318 (59); Stoll, R. R., 21 (49; 850), 808 (666); Stone, A. H., (828); Stone, D. M., 30 (49; 850), 31 (49; 857); Szász, O., 471 (344), 808 (671), (825).

Thrall, R. M., 31 (49; 851), 474 (335); Thron, W. J., 320 (60), 811 (498); Trjitzinsky, W. J., 30 (60), 808 (671); Tucker, A. W., 808 (681); Tukey, J. W., 471 (348).

Ulam, S. M., 30 (57), 30 (61), 31 (60), 811 (496). 
Valentine, F. A., 475 (344), Vazsonyi, A., 319 (188), 808 (673); Vinograde, B., 474 (335).

Wald, A., 808 (679), 808 (679); Wall, H. S., 30 (49; 691), 811 (672), (672); Walsh, J. L., 811 (670); Wang, F. T., 320 (184), 320 (184); Warschawski, S. E., 30 (61), 474 (344); Wehausen, J. V.. 30 (49; 858); Weinstein, A., (826); Wetzel, M., 30 (49; 691); Wheeler, A. H., 809 (500); White, P. A., 811 (502), (828); Whitehead, G. W., (828); Whitman, P. M., 318 (180), 320 (179); Whyburn, G. T., 32 (65), 472 (502); Widder, D. V., 320 (185); Wilcox, L. R., 31 (55), 32 (62); Wilkins, J. E., 474 (347), (826); Williamson, J., 471 (336); Wolf, F., 162 (63); Wolfowitz, J., 808 (679); Wong, Y. C., 811 (677), 811 (677).

Young, G. S., 474 (350), 475 (349), 475 (350); Youngs, J. W. T., 30 (49; 867).

Zariski, O., 472 (501); Zygmund, A., $22(49 ; 858)$.

\section{INDEX OF REPORTS OF MEETINGS AND MISCELLANEOUS ARTICLES}

Aid to libraries in war areas, 816.

Ayres, W. L. Report of meeting of the American Mathematical Society: Annual meeting of the Society, 23.

Birkhoff, G. D. Edward Burr Van Vleck-In Memoriam, 37.

Bliss, G. A. Oskar Bolza-In Memoriam, 478.

Bolza, O. See Bliss, G. A.

Fiske, T. S. See Fite, W. B.

Fite, W. B. Thomas Scott Fiske-In Memoriam, 283.

Hancock, H. See Moore, C. N.

Hilbert, D. See Weyl, H.

Hollcroft, T. R. Reports of meetings of the American Mathematical Society: October meeting in New York, 20; February meeting in New York, 317; Summer meeting in Wellesley, 803.

Kline, J. R. Report of meeting of the American Mathematical Society: April meeting in New York, 464.

See Stone, M. H.

Koopman, B. O. William Fogg Osgood-In Memoriam, 139.

Michal, A. D. Reports of meetings of the American Mathematical Society: November meeting in Pasadena, 161; A pril meeting in Berkeley, 476.

Moore, C. N. Harris Hancock-In Memoriam, 812.

Osgood, W. F. See Koopman, B. O.

Stone, M. H., and Kline, J. R. Mathematicians and the new selective service regulations, 1.

Van Vleck, E. B. See Birkhoff, G. D.

Weyl, H. David Hilbert and his mathematical work, 612.

Youngs, J. W. T. Report of meeting of the American Mathematical Society: April meeting in Chicago, 473.

\section{INDEX OF BOOK REVIEWS}

Busemann, H. Metric methods in Finsler spaces and in the foundations of geometry. F. A. Ficken, 321.

See Weyl, H.

Church, A. The calculi of lambda-convergence. O. Frink, 169.

Coburn, N. See Craig, H. V.

Craig, H. V. Vector and tensor analysis. N. Coburn, 490. 
Ficken, F. A. See Busemann, H.

Frink, O. See Church, A.

Hodge, W. V. D. The theory and applications of harmonic integrals. D. J. Struik, 43.

Miller, F. H. Partial differential equations. E. W. Titt, 168.

Struik, D. J. See Hodge, W. V. D.; Takasu, T.

Takasu, T. Differentialgeometrien in den Kugelraumen. Vol. II. Laguerresche Differentialkugelgeometrie. D. J. Struik, 42.

Thompson, D. W. On growth and form. J. W. Wilson, 163.

Titt, E. W. See Miller, F. H.

Weyl, H., and Weyl, J. Meromorphic functions and analytic curves. H. Busemann, 655.

Weyl, J. See Weyl, H.

Wilson, J. W. See Thompson, D. W.

\section{INDEX OF ADDRESSES}

Baer, R. The higher commutator subgroups of a group, 143.

Lorch, E. R. The structure of normed abelian rings, 447.

Martin, W. T. Mappings by means of systems of analytic functions of several complex variables, 5.

Mises, R. v. Integral theorems in three-dimensional potential flow, 599.

Post, E. L. Recursively enumerable sets of positive integers and their decision problems, 284.

Robinson, R. M. Hadamard's three circles theorem, 795.

\section{INDEX OF RESEARCH PAPERS}

Agnew, R. P. Summability of subsequences, 596.

Alaoglu, L., and Erdös, P. A conjecture in elementary number theory, 881.

Albert, A. A. Two element generation of a separable algebra, 786.

Albert, G. E., and Miller, L. H. Equiconvergence theorems for orthonormal polynomials, 358.

Baer, R. Groups without proper isomorphic quotient groups, 267.

See Index of Addresses.

Basoco, M. A. On certain arithmetical functions due to G. Humbert, 547.

Bateman, H. Some integral relations, 745.

Bellman, R. Almost orthogonal series, 517.

- A note on an inequality of E. Schmidt, 734.

- A note on a theorem of Hardy on Fourier constants, 741.

Bergman, S. The determination of some properties of a function satisfying a partial differential equation from its series development, 535.

Birkhoff, G. Subdirect unions in universal algebra, 764.

Bissinger, B. H. A generalization of continued fractions, 868.

Blumenthal, L. M. Distance geometry notes, 235.

Brown, H. K. Resolution of temperature problems by the use of finite Fourier transformations, 376.

Bruck, R. H. Simple quasigroups, 769.

Buck, R. C. Limit points of subsequences, 395.

Chang, S. C. On the quadrics associated with a point of a surface, 926.

Chevalley, C. On the notion of the ring of quotients of a prime ideal, 93.

Clark, C. E. The symmetric join of a complex, 81.

Clippinger, R. F. Matrix products of matrix powers, 368.

Cohen, L. W. On linear equations in Hilbert space, 729. 
Cowling, V. F., Leighton, W., and Thron, W. J. Twin convergence regions for continued fractions, 351.

Day, M. M. Cluster points of subsequences, 398.

DeCicco, J. See Kasner, E.

Dowker, C. H. On minimum circumscribed polygons, 120.

Eilenberg, S., and Niven, I. The "fundamental theorem of algebra" for quaternions, 246.

Erdös, P. Some remarks on connected sets, 442.

- See Alaoglu, L.

Farnell, A. B. Limits for the characteristic roots of a matrix, 789.

Feld, J. M. On a representation in space of groups of circle and turbine transformations in the plane, 930.

Fine, N. J., and Niven, I. The probability that a determinant be congruent to a $(\bmod m)$, 89.

García, M. Component orbits under pointwise recurrent homeomorphisms, 260.

Geronimus, J. On Gauss' and Tchebycheff's quadrature formulas, 217.

Gottschalk, W. H. Powers of homeomorphisms with almost periodic properties, 222.

- Orbit-closure decompositions and almost periodic properties, 915.

Grove, V. G. The transformation of Cech, 231.

Hadamard, J. Two works on iteration and related questions, 67.

A known problem of geometry and its cases of indetermination, 520.

Hall, D. W. On rotation groups of plane continuous curves under pointwise periodic homeomorphisms, 715.

Halmos, P. R. Comment on the real line, 877.

Hill, J. D. Some properties of summability. II, 227.

Huff, G. B. The completion of a theorem of Kantor, 692.

Hughes, H. K. On the asymptotic expansions of entire functions defined by Maclaurin series, 425.

Hsiung, C. C. Projective invariants of intersection of certain pairs of surfaces, 437.

Hull, R. A theorem on the unit groups of simple algebras, 405.

Jackson, S. B. Vertices of plane curves, 564.

Jacobson, N. Schur's theorems on commutative matrices, 431.

The equation $x^{\prime} \equiv x d-d x=b, 902$.

Jennings, S. A. A note on chain conditions in nilpotent rings and curves, 759.

Johnson, R. E. On the equation $\chi \alpha=\gamma \chi+\beta$ over an algebraic division ring, 202.

Kaplansky, I. Symbolic soiution of certain problems in permutations, 906.

Kasner, E., and DeCicco, J. Union-preserving transformations of space, 98.

Kormes, J. P. The solution of the differential equation $\left(a^{2} \partial^{2} / \partial t^{2}-\Delta\right)\left(\partial^{2} / \partial t^{2}-\Delta\right) u$ $=f(x, y, z, t)$ by Hadamard's method, 842 .

Lax, P. D. Proof of a conjecture of $P$. Erdos on the derivative of a polynomial, 509.

Leighton, W. See Cowling, V. F.

Loomis, L. H. A short proof of the completeness of the Laguerre functions, 386. An elementary proof of the strong form of the Cauchy theorem, 831.

Lorch, E. R. See Index of Addresses.

Lotkin, M. On a certain type of nonlinear integral equations, 833.

MacDonald, J. Conjugate nets in asymptotic parameters, 697.

Mackey, G. W. Equivalence of a problem in measure theory to a problem in the theory of vector lattices, 719.

MacQueen, M. L. The extremals of two invariant integrals, 503.

Mann, H. B. On orthogonal Latin squares, 249.

_-On certain systems which are almost groups, 879. 
Marden, M. A recurrence formula for the solutions of certain linear partial differential equations, 208.

Martin, W. T. See Index of Addresses.

Miller, L. H. See Albert, G. E.

Mises, R. v. See Index of Addresses.

Morse, A. P. The role of internal families in measure theory, 723.

Nielsen, K. L. On the Bergman operators for linear partial differential equations, 195.

Niven, I. See Eilenberg, S.; Fine, N. J.

Peach, M. O. Simplified technigue for constructing orthonormal functions, 556.

Pollard, H. Fourier series with coefficients in a Banach space, 581.

The mean convergence of non-harmonic series, 583.

Post, E. L. See Index of Addresses.

Robbins, H. E. Two properties of the function $\cos x, 750$.

Robinson, R. M. See Index of Addresses.

Rosenthall, E. On some special diphantine equations, 753.

Salem, R. On a theorem of Bohr and Pal, 579.

Salzer, H. E. A new formula for inverse interpolation, 513.

Santal6, L. A. Note on convex spherical curves, 528.

Schilling, O. F. G. Automorphisms of fields of formal power series, 892.

Simons, W. H. Congruences involving the partition function $p(n), 883$.

Smiley, M. F. An application of lattice theory to quasigroups, 782.

Sorgenfrey, R. H. Some theorems on co-terminal arcs, 257.

Szász, O. On uniform convergence of Fourier series, 587.

- On uniform convergence of trigonometric series, 856.

Tamarkin, J. D., and Zygmund, A. Proof of a theorem of Thorin, 279.

Thron, W. J. See Cowling, V. F.

Transue, W. R. Remarks on transitivities of betweenness, 108.

Valentine, F. A. Contractions in non-Euclidean spaces, 710.

Wall, H. S. Continued fractions and bounded analytic functions, 110.

Wallace, A. D. A substitute for the axiom of choice, 278.

Wang, F. T. On strong summability of a Fourier series, 412.

- A note on Riesz summability of the type $e^{n \alpha}, 417$.

- On Riesz summability of Fourier series by exponential means, 420.

Wang, H. C. On the paths with Monge's equations of the second degree as conditions of intersection, 935.

Webber, G. C. Transcendence of certain continued fractions, 736.

White, P. A. On r-regular convergence, 123.

Whitney, H. On the extension of differentiable functions, 76.

Topics in the theory of abelian groups. I. Divisibility of homomorphisms, 129.

Wilcox, L. R. Modularity in Birkhoff lattices, 135.

Wilkins, J. E. On the growth of solutions of linear differential equations, 388.

Whyburn, G. T. Topological analog of the Weierstrass double series theorem, 242.

Yang, C. N. On the uniqueness of Young's differentials, 373.

Young, G. S. A generalization of Moore's theorem on simple triods, 714. On continua whose links are non-interesecting, 920.

Zariski, O. The compactness of the Riemann manifold of an abstract field of algebraic functions, 683.

Zygmund, A. See Tamarkin, J. D. 